(C) Facultad de Ciencias Biológicas UNMSM

\title{
Aplicación de dos biomarcadores para el análisis de lesiones en el DNA de bivalvos marinos
}

\author{
Application of two biomarkers for the analysis of DNA lesions on marine \\ bivalves
}

\author{
Giovanna Sotil, Rafael Alvis, Juan C. Francia y Betty Shiga
}

Universidad Nacional Mayor de San Marcos, Facultad de Ciencias Biológicas, Apartado 110058, Lima 11, Perú.

Email Gionanna Sotil: gsotil@yahoo.com

\begin{abstract}
Resumen
El presente trabajo describe la estandarización de las técnicas del Test de Micronúcleo (MN) y Ensayo Cometa para la evaluación del daño en el DNA de bivalvos marinos. La importancia de estas técnicas radica en que permiten evaluar la respuesta temprana al estrés ocasionado por agentes contaminantes y cambios ambientales. Tejidos branquiales de Semimytilus algosus y Aulacomya ater fueron utilizados para tratamientos in vivo e in vitro. Los tejidos fueron expuestos a los agentes mutagénicos Mitomicina $C$ en concentraciones de 0,02; 0,04 y 0,06 x $10^{-6} \mathrm{M}$ y $\mathrm{H}_{2} \mathrm{O}_{2}$ en una concentración de $100 \mu \mathrm{M}$ con tiempos de evaluación de 1, 3, 6, 24 y $48 \mathrm{~h}$. Diferentes soluciones para la colecta del tejido y aislamiento celular fueron evaluados obteniendo una mayor viabilidad celular en la solución salina CMFS, pH 7,3; en frío. El Test de Micronúcleo se modificó en la forma de obtener el disgregado celular, realizando la hipotonización en Citrato de sodio $0,9 \%$, fijación en metanol por segundos posterior al frotis y la tinción con Giemsa $2 \%$. La estandarización del Ensayo Cometa Alcalino, descrita por Wilson et al. (1998), se realizó modificando la suspensión celular en agarosa LMP (1\% en solución Kenny, pH 7,5), la exposición a solución de lisis ( $\mathrm{pH} 10$ con DMSO y Tritón) con variaciones en el tiempo de 1 a 16 h, y la electroforesis en solución alcalina pH 13,7 y tinción con Bromuro de etidio y Nitrato de plata para geles de agarosa. Los cambios realizados en ambas técnicas permitieron obtener un alto número celular con morfología definida, observándose macrolesiones como la formación de MN y aberraciones nucleares, y la determinación cualitativa de microlesiones observadas por fragmentación y migración del DNA.
\end{abstract}

Palabras claves: daño del DNA, micronúcleo, Ensayo Cometa alcalino, estrés, bivalvos

Abstract

This work describes the standardization of Micronucleus Assay (MN) and Comet Assay techniques used for the evaluation of the DNA damage on marine bivalves. These techniques are important because they can evaluate the early stress response caused by pollutant agents and environmental changes. Branchial tissues of Semimytilus algosus and Aulacomya ater were used for in vivo and in vitro treatments. Tissues were exposed to the mutagenetic agents Mitomicine $C$ in concentrations of 0,$02 ; 0,04$ and $0,06 \times 10^{-6} \mathrm{M}$ and $\mathrm{H}_{2} \mathrm{O}_{2}$ in concentration of $100 \mu \mathrm{M}$ evaluated at 1, 3, 6, 24 and $48 \mathrm{~h}$. Different solutions for the tissue collection and cell isolation were evaluated, obtaining more cell viability with cold $\mathrm{CMFS}$ pH 7,3 saline solution. Micronucleus Assay were modified in the obtaining of suspension cell, we used $0,9 \%$ Sodium citrate hipotonic solution, fixation in methanol for seconds after the spread and dyed with $2 \%$ Giemsa. The Alkaline Comet Assay protocol described by Wilson et al. (1998) was standardized modifying the single-cell suspension embedded in LMP Agarose (1\% in Kenny solution, $\mathrm{pH} 7,5)$, the exposure at lysing solution ( $\mathrm{pH} 10$ with DMSO and Triton) with changes from 1 to $16 \mathrm{~h}$, electrophoresis in alkaline solution $\mathrm{pH}$ 13,7 and dyed with Ethidium bromide and Silver nitrate for agarose gels. Changes made at both techniques allowed us to obtain a high cell number with a defined morphology, recognizing macrolessions like the $\mathrm{MN}$ formation and nuclear aberrations, and the qualitative determination of microlessions observed by the fragmentation and migration of the DNA.

Keywords: DNA damage, micronucleus, Alkaline Comet assay, stress, bivalves

\section{Introducción}

La presencia de contaminantes en ambientes marinos sumados a los cambios ambientales son factores causantes del estrés celular, el cual se manifiesta en la mortalidad de los individuos, mutaciones y pérdida de la diversidad genética de las poblaciones.

Varias técnicas citogenéticas y moleculares han sido utilizadas como biomarcadores para el monitoreo de la contaminación en ambientes acuáticos, así como para la detección de respuestas tempranas al estrés de forma previa a la ocurrencia de cambios en la dinámica poblacional. Entre los organismos acuáticos, los moluscos por su capacidad de filtración y su amplia distribución, son empleados como indicadores por acumular compuestos en sus tejidos, con efectos diversos dependiendo de la capacidad de tolerancia y mecanismos de detoxificación del individuo (Singh \& Stephens, 1997).

Una de las técnicas utilizadas para la evaluación de macrolesiones en el material genético es el Test de Micronúcleo (MN). Inicialmente descrita por Schmid (1975) para células de mamíferos, este test permite la observación de los micronúcleos como masas de cromatina intracitoplasmáticas separadas del núcleo, producidas por la fragmentación del DNA debido a efectos del daño 
mutagénico (Scarpato et al., 1990). Otra de las pruebas utilizadas es el Ensayo Cometa (Ostling \& Johanson, 1984; Ralph et al., 1996), basado en la migración de fragmentos rotos del DNA durante la electroforesis (Lee \& Steinert, 2003). Este ensayo es utilizado para el análisis de microlesiones presentando ventajas respecto a los métodos citogenéticos por su alta sensibilidad y posibilidad de evaluarse en células que no se encuentran en división (Singh et al., 1988).

Trabajos in vitro e in vivo realizados en células de tejido branquial, hemocitos y hepatocitos de individuos del género Mytilus, reportan el efecto tóxico de compuestos como ciclofosfamida, peróxido de hidrógeno $\left(\mathrm{H}_{2} \mathrm{O}_{2}\right)$, cobre (Majone et al., 1988) y benzo(a)pireno (Dolcetti \& Venier, 2002); observándose cambios en las frecuencias de $\mathrm{MN}$ relacionados con la concentración y tiempos de exposición, así como lesiones ocurridas a nivel de cadenas simples o dobles del DNA evaluadas mediante modificaciones de la técnica del Ensayo Cometa (Pavlica et al., 2001; Venier et al., 1997). Sin embargo, pocos son los estudios que evalúan la interacción de los cambios ambientales y la presencia de contaminantes con la biología del organismo, factores que estarían produciendo alteraciones en el ciclo celular y en la organización del DNA (Bascomb, 1982; Anitha et al., 2000).

En el presente trabajo describimos la estandarización del Test de Micronúcleo y el Ensayo Cometa en células branquiales para dos especies de bivalvos marinos Semimytilus algosus y Aulacomya ater expuestos a Mitomicina $\mathrm{C}(\mathrm{MMC})$ y $\mathrm{H}_{2} \mathrm{O}_{2}$. Se analizó la sensibilidad de la técnica de $\mathrm{MN}$ comparando muestras in situ e in vivo bajo diferentes temperaturas. Además se identificaron cualitativamente niveles de daño en el DNA mediante el Ensayo Cometa en un medio alcalino con tratamientos in vitro. Las modificaciones en ambas técnicas mejoran sensiblemente la calidad de los resultados, y demuestran su utilidad y fácil manejo en la evaluación del estrés inducido por variaciones ambientales.

\section{Material y métodos Material biológico}

Durante los meses de enero a mayo se realizaron colectas de individuos de Semimytilus algosus de 4 a $5 \mathrm{~cm}$ de longitud, en la zona intermareal rocosa de la Playa San Francisco -Ancón, Lima $\left(11^{\circ} 46^{\prime} \mathrm{S}, 77^{\circ} 11^{\prime} \mathrm{W}\right)$. Los ejemplares fueron transportados al laboratorio en agua de mar y colocados en acuarios de vidrio para los experimentos in vivo. Se colocaron 5 individuos de $S$. algosus por acuario conteniendo 0,51 de agua de mar, donde fueron aclimatados $24 \mathrm{~h}$ previas al tratamiento, a temperaturas de $11^{\circ} \mathrm{C}$ y $23^{\circ} \mathrm{C}$, con fotoperiodo de $12 \mathrm{~h}$ luz y $12 \mathrm{~h}$ noche. También fueron colectados otros individuos de los cuales se extrajeron muestras de tejido en el momento de colecta, y mantenidos en solución salina fría para ser procesados en el laboratorio con las técnicas correspondientes; éstas fueron consideradas como evaluación in situ. Los tratamientos in vitro se realizaron en tejido branquial de la especie de fondo duro Aulacomya ater, considerando individuos de $7 \mathrm{~cm}$ de longitud, colectados de la Isla Santa Rosa, Bahía Independencia $\left(14^{\circ} 19^{\prime} \mathrm{LS}, 76^{\circ} 07^{\prime} \mathrm{LW}\right)$.

\section{Test de Micronúcleo}

Ejemplares de $S$. algosus fueron expuestos por $48 \mathrm{~h}$ a concentraciones de 0,$02 ; 0,04$ y $0,06 \times 10^{-6} \mathrm{M}$ de MMC para cada temperatura, con una réplica y recambios diarios de agua, evaluando a 1,3 , 6, 24 y $48 \mathrm{~h}$. Las branquias fueron extraídas a $10^{\circ} \mathrm{C}$ utilizando una solución hipotónica de Citrato de sodio, probando concentracio- nes de $0,9 \%$ y $1,2 \%$. Para el disgregado celular, se probaron diferentes soluciones fisiológicas de mantenimiento como CMFS (Calcium magnesium free solution) $\mathrm{pH}$ 7,3 y otras preparadas en agua de mar con Hepes, Borax, Hepes-Borax, Hepes-BSA (bovine serum albumin), Citrato-Borax y Tripsina. La viabilidad celular fue evaluada utilizando Eosina Y al 0,1\% en CMFS. La suspensión celular fue filtrada en un tamiz de nylon de $40 \mu \mathrm{m}$ de diámetro de poro. Luego, $150 \mu$ l de la muestra fueron colocados en una lámina mediante frotis y secado a temperatura ambiente durante $24 \mathrm{~h}$. Se probaron dos tipos de fijador, Carnoy (ácido acético glacial 1:3 metanol absoluto) y metanol absoluto, ambos a $4{ }^{\circ} \mathrm{C}$ por $10 \mathrm{~min}$. Las láminas fueron coloreadas utilizando Giemsa al $2 \%$ por 20 min y montadas con Entellán. La cuantificación de MN se realizó de acuerdo a los parámetros establecidos por Wrisberg et al. (1992) que considera MN de tamaño igual o menor a un tercio del núcleo, y las aberraciones nucleares de acuerdo a Venier et al. (1997) y Majone et al. (1987) considerándose a los núcleos irregulares. Se evaluaron por cada individuo 1000 células con citoplasma completo, agranulares y de morfología definida, en un microscopio óptico a $1000 \mathrm{X}$.

\section{Ensayo Cometa}

El Ensayo Cometa Alcalino fue estandarizado utilizando tratamientos in vitro en tejido branquial de $A$. ater a partir del protocolo descrito por Wilson et al. (1998). La extracción del tejido y aislamiento de células se realizó en CMFS a $10^{\circ} \mathrm{C}$, bajo luz amarilla para evitar el daño por ondas UV. Previamente las láminas fueron cubiertas con Agarosa Normal Melting Point (NMP) probando diferentes concentraciones entre 1 a $2 \%$ en Buffer Tae $1 \mathrm{X}$ y almacenándolas a $10^{\circ} \mathrm{C}$ por $24 \mathrm{~h}$. El tejido fue lavado dos veces en $2 \mathrm{ml}$ de CMFS, trozado y mantenido en $6 \mathrm{ml}$ de la solución salina, expuestos a $100 \mu \mathrm{M}$ de $\mathrm{H}_{2} \mathrm{O}_{2}$ por $1 \mathrm{~h}$. La suspensión celular fue filtrada y centrifugada por $7 \mathrm{~min}$. El precipitado fue resuspendido en $2 \mathrm{ml}$ de CMFS para evaluar la viabilidad celular utilizando Eosina Y $0,1 \%$. Se centrifugó la suspensión celular por $10 \mathrm{~min}$, resuspendiendo el precipitado a diferentes volúmenes (100, 150 y $200 \mu \mathrm{l})$ de Agarosa Low Melting Point (LMP) en concentraciones de $1 \%$ y $2 \%$, disuelta a $35^{\circ} \mathrm{C}$ en Solución salina de Kenny pH 7,5 $\left(0,4 \mathrm{M} \mathrm{NaCl} ; 9 \mathrm{mM} \mathrm{KCl} ; 0,7 \mathrm{mM} \mathrm{K}_{2} \mathrm{HPO}_{4} ; 2 \mathrm{mM} \mathrm{NaHCO}_{3}\right)$. Se colocaron $50 \mu \mathrm{l}$ de muestra en la lámina hasta gelificar. Las láminas fueron expuestas a solución Lisis pH 10 (2,5 M NaCl; 10 mM Tris; 100 mM EDTA, 1\% Sarcosyl, 1\% Triton X-100, 10\% DMSO) a 4 ${ }^{\circ} \mathrm{C}$, evaluando tiempos entre 1 a $16 \mathrm{~h}$, lavadas con agua destilada y colocadas en la cámara electroforética con solución alcalina $\mathrm{pH}>$ 13,7 ( NaOH-EDTA) por $10 \mathrm{~min}$ a $11^{\circ} \mathrm{C}$. La corrida electroforética se realizó a $20 \mathrm{~V}, 300 \mathrm{~mA}$ por $15 \mathrm{~min}$. Las láminas fueron retiradas de la cámara y sumergidas en Buffer de Neutralización pH 7,5 (0,4 $\mathrm{M}$ Tris) a temperatura ambiente, dejándolas secar por $30 \mathrm{~min}$. Se probaron dos tipos de tinción. Para fluorescencia con Bromuro de etidio, las láminas fueron fijadas con metanol absoluto y visualizadas en un microscopio a $400 \mathrm{X}$, utilizando filtros de excitación de 420—490 nm y de emisión de $520 \mathrm{~nm}$. Para la tinción con Nitrato de plata, las láminas fueron fijadas con solución Ácido tricloroacético 15\%, sulfato de zinc 5\% y glicerol 5\%, según el protocolo descrito por Nadin et al. (2001), y observadas en un microscopio óptico a $400 \mathrm{X}$.

\section{Resultados \\ Test de Micronúcleo}

La eficiencia de las diferentes soluciones fisiológicas para las preparaciones citológicas fue evaluada mediante la prueba de via- 


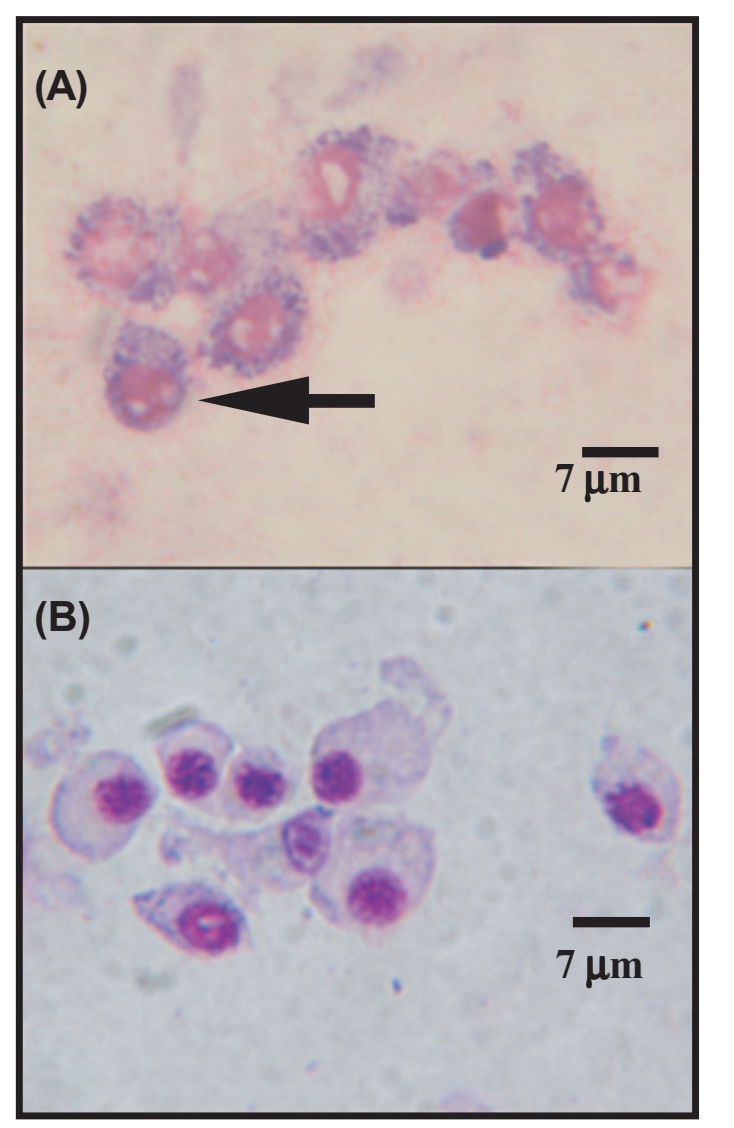

Figura 1. Células branquiales de $S$. algosus procesadas con tripsina $(\mathrm{A})$ y solución salina CMFS $(\mathrm{B})$ durante el disgregado celular. (Flecha) indica la presencia de vesículas en células con morfología no definida.

bilidad con Eosina Y, obteniendo células de mejor calidad con CMFS alcanzando un rango de 70 a $80 \%$ de células vivas, de acuerdo a los valores sugeridos por Singh et al. (1988). Además, la hipotonización celular con Citrato de sodio $0,9 \%$ durante $1 \mathrm{~min}$ previo al CMFS permitió una mejor diferenciación del citoplasma y del núcleo, con un escaso efecto sobre la viabilidad y morfología celular. La fijación con Carnoy (3:1) sugerida para el género Mytilus

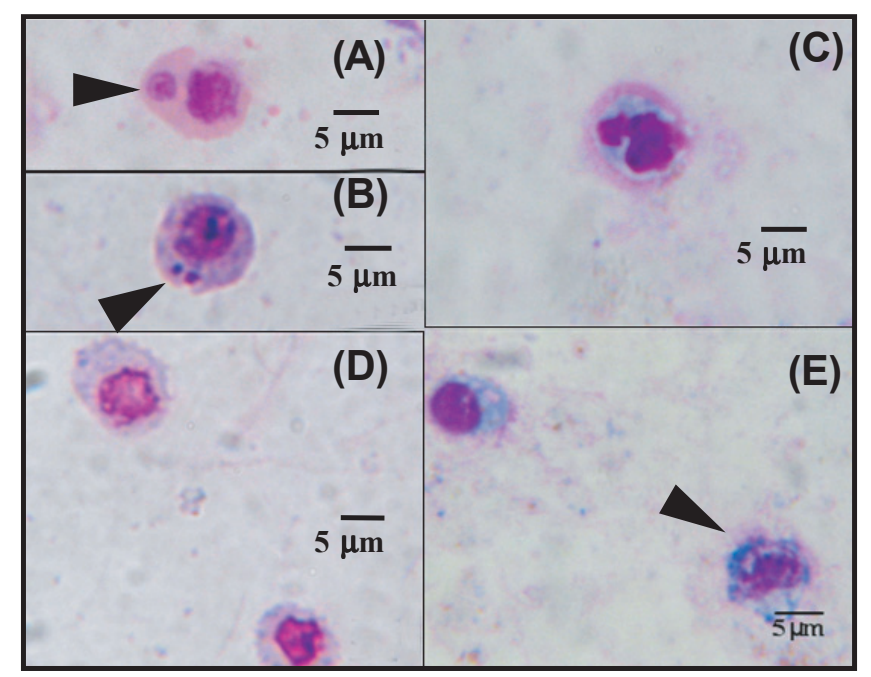

Figura 2. Macrolesiones observadas en células branquiales de $S$. algosus. Se diferenciaron células con presencia de (A) un micronúcleo, (B) dos micronúcleos, y aberraciones nucleares (C) de forma arriñonada, (D) con núcleo no uniforme y membrana nuclear rota, y (E) núcleo fragmentado.

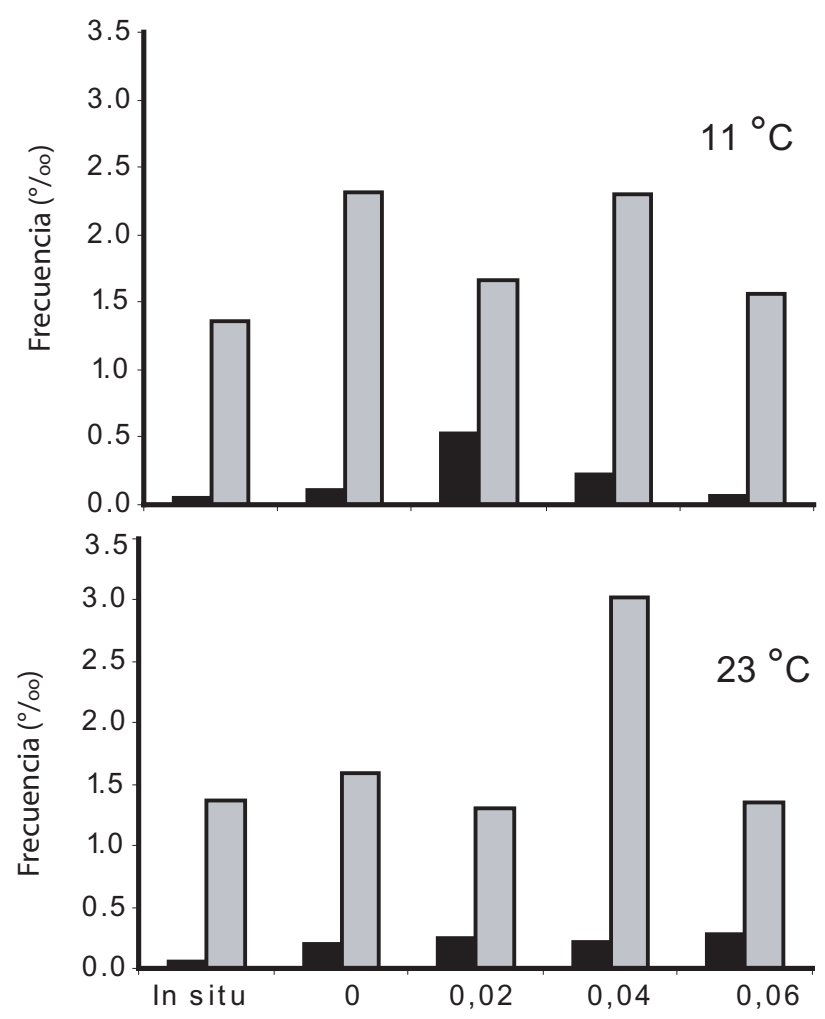

Figura 3. Frecuencias $(\%)$ de micronúcleos $(\mathrm{MN})$ y aberraciones nucleares $(\mathrm{AB})$ en células branquiales de $S$. algosus expuestos a $\mathrm{MMC}\left(\mathrm{x} 10^{-6} \mathrm{M}\right)$ a $11^{\circ} \mathrm{C}$ y $23^{\circ} \mathrm{C}$.

(Dailianis et al., 2003; Scarpato et al., 1990) no resultó, obteniendo células aglutinadas con citoplasmas fragmentados, también reportado para la especie M. galloprovincialis (Venier et al., 1997). Una adecuada fijación celular se obtuvo utilizando metanol absoluto también reportado para mitílidos y peces (De Flora et al., 1993) (Fig. 1 B).

Se observaron dos tipos celulares, células pequeñas caracterizadas por un núcleo oscuro compacto; y otras más grandes con núcleo redondeado de cromatina uniforme (Dixon et al., 2002 y Scarpato et al., 1990), considerándolas para la cuantificación de aberraciones y MN de acuerdo a los parámetros establecidos por Wrisberg et al. (1992). Los MN fueron cuantificados y expresados en frecuencias (Fig. 2 A y B). Tres tipos de aberraciones nucleares fueron diferenciadas: forma arriñonada (Fig. 2 C), no uniforme con membrana nuclear rota (Fig. 2 D), y fragmentación del núcleo (Fig. 2 E).

Los individuos evaluados in situ presentaron una baja frecuencia de $\mathrm{MN}\left(0,06^{\circ} \%\right.$ oo $)$ respecto a los tratamientos en laboratorio. Pocos MN se observaron entre 1 a 24 h de exposición, presentando un incremento considerable a partir de $48 \mathrm{~h}$. Los tratamientos controles presentaron una variación de acuerdo a la temperatura, con frecuencias de $0,1^{\circ} /$ oo, $0,2^{\circ}$ oo para $11^{\circ} \mathrm{C}$ y $23^{\circ} \mathrm{C}$ respectivamente. A los $11^{\circ} \mathrm{C}$ con $0,02 \times 10^{-6} \mathrm{M}$ de $\mathrm{MMC}$, el incremento máximo fue de $0,53^{\circ} \%$ oo, mientras que a $23^{\circ} \mathrm{C} \operatorname{con} 0,04 \times 10^{-6} \mathrm{M}$ el máximo fue de $0,35^{\circ}$ oo. Para ambas temperaturas a 0,06 × $10^{-}$ ${ }^{6} \mathrm{M}$ de MMC disminuyó la frecuencia de MN (Fig. 3).

\section{Ensayo Cometa}

Se estandarizó la técnica realizando modificaciones en el procesamiento de la muestra, concentración de agarosas, tiempos de 

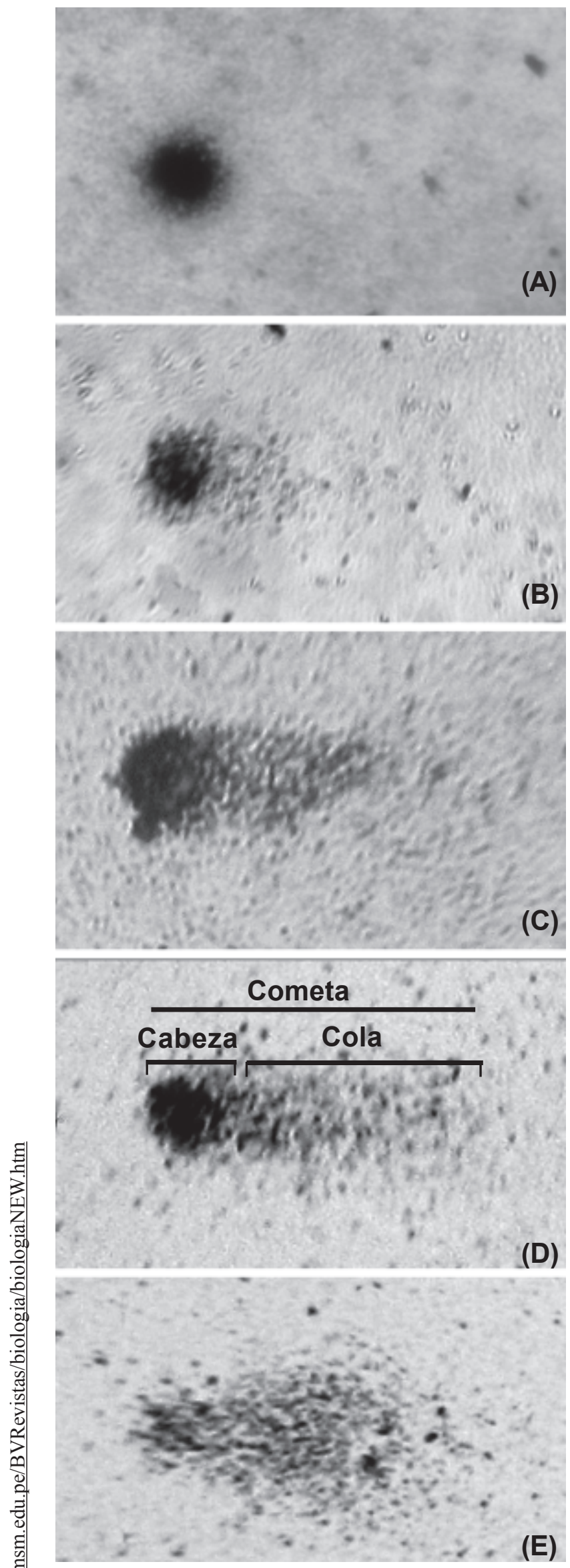

Figura 4. Niveles de daño en el DNA de células branquiales de $A$. ater expuestas a $\mathrm{H}_{2} \mathrm{O}_{2}$ observadas con la técnica del Ensayo Cometa (tinción con nitrato de plata). (A) Grado 0 o célula sin daño, (B) Grado 2, (C) Grado 3, (D) Grado 4, (E) apoptosis con núcleo poco diferenciado. (750X) lisis y técnicas de coloración. El daño en el DNA se diferenció teniendo en cuenta la cantidad de DNA compacto mantenido en el núcleo denominado como «cabeza» en comparación con la cantidad de DNA migrado hacia el ánodo llamado «cola». Establecimos un patrón de clasificación considerando 5 niveles: Grado 0 o células no dañadas, sin cola (Fig. 4 A); grado 1 o células ligeramente dañadas, con cola menor al tamaño de la cabeza (Fig. 4 B), grado 2 o células dañadas, con cola igual al tamaño de la cabeza (Fig. 4 C), grado 3 o células fuertemente dañadas, con cola mayor al tamaño de la cabeza (Fig. 4D), y grado 4 o células en apoptosis (Fig. 4 E).

\section{Discusión}

Las mejoras que realizamos en los protocolos (Scarpato et al., 1990; Wrisberg et al., 1992; Wilson et al., 1998; Singh et al., 1988; Nadin et al., 2001) para el Test de MN y Ensayo Cometa en mitílidos, nos permitieron diferenciar y clasificar macrolesiones y microlesiones en células del tejido branquial en $S$. algosus y $A$. ater. La solución salina CMFS, generalmente utilizada para el mantenimiento celular en el Ensayo Cometa, fue probada para la evaluación en el Test de MN reduciendo la cantidad de rupturas en la membrana citoplasmática, logrando un incremento de la viabilidad celular y permitiendo la detección de lesiones en el DNA, en comparación con las soluciones conteniendo Hepes, Borax o BSA. La disgregación enzimática con Tripsina utilizada por algunos autores (Majone et al., 1988; Dolcetti \& Venier, 2002) provocó daños en la membrana celular y un incremento de las inclusiones citoplasmáticas (Fig. 1.A), aspecto negativo también reportado para células de M. galloprovincialis (Venier, et al., 1997).

La MMC es un agente genotóxico con efectos mutagénicos tanto para mamíferos como para organismos marinos.

Incrementos en las frecuencias de MN se han reportado en tratamientos in vitro de M. galloprovincialis (Majone et al., 1987; Dixon et al., 2002). Similar efecto observamos en los tratamientos in vivo de $S$. algosus a partir de las $48 \mathrm{~h}$, tiempo relacionado con el proceso de la replicación celular (Dixon et al., 2002). En altas concentraciones de MMC observamos una reducción en la cantidad de MN. Aparentemente los incrementos en la concentración y tiempos de exposición a agentes mutagénicos estarían inhibiendo la actividad mitótica (Dailianis et al., 2003).

El $\mathrm{H}_{2} \mathrm{O}_{2}$ es un compuesto comúnmente utilizado para producir daño en el DNA por lo que ha sido utilizado en estudios de contaminación como un patrón de comparación (Singh et al., 1988; Rank y Jensen, 2003; Mitchelmore et al, 1996). Los tratamientos realizados in vitro de $A$. ater expuestos a este agente, permitieron identificar y clasificar los diferentes grados de lesiones en el DNA. Variaciones en el daño del DNA se relacionan con los incrementos en las concentraciones del $\mathrm{H}_{2} \mathrm{O}_{2}$ que mediante la evaluación del Ensayo Cometa Alcalino se evidencian como variaciones en la longitud de la migración del DNA, siendo un indicador de rupturas de las hebras.

Sin embargo, estas macro y microlesiones pueden variar de acuerdo a los cambios estacionales y a las características fisiológicas de los organismos. Factores como la edad, crecimiento del organismo y estado hormonal (Dixon et al., 2002), influyen de manera importante en los sistemas enzimáticos de activación y detoxificación genotóxica (Mitchelmore et al., 1998), lo cual convierte a estas pruebas en importantes instrumentos para medir el impacto del estrés causado por los cambios ambientales. 


\section{Agradecimientos}

Este estudio fue parcialmente financiado por el proyecto CENSOR - EU (Climate variability and El Niño Southern Oscillation: impacts for natural resources and management - Contrato 511071) y es una publicación CENSOR 0110 (Responsable Dr. Juan Tarazona, UNMSM). Los autores agradecen al Blgo. José Luis Pino, Blgo. José Gonzales, Blga. Margarita Velásquez, Blgo. Leonardo Romero, Mag. César Córdova, Mag. Fernando Retuerto de la Facultad de Ciencias Biológicas, y al Lab. de Ácidos Nucleicos y Biología Molecular del Centro de Investigación de Bioquímica y Nutrición.

\section{Literatura citada}

Anitha, B., N. Chandra, P.M. Gopinath \& G. Durairaj, 2000. Genotoxicity evaluation of heat shock in gold fish (Carassius auratus). Mutation Research, 469: 1-8.

Bascomb, W. 1982. The effects of waste disposal on the coastal waters of Southern California. Environmental Science and Technology, 16: 226-235.

Dailianis, S., G.P. Domouhtsidou, E. Raftopoulou, M. Kaloyianni \& V.K. Dimitriadis. 2003. Evaluation of neutral red retention assay, micronucleus test, acetylcholinesterase activity and a signal transduction molecule (cAMP) in tissues of Mytilus galloprovinciales (L.) in pollution monitoring. Marine Environmental Research, 56: 443-470.

De Flora, S., L. Vigano, F. D’Agostini, A. Camoirano, M. Bagnasco, C. Bennicelli, F. Melodia \& A. Arillo. 1993. Multiple genotoxicity biomarkers in fish exposed in situ to polluted river water. Mutation Research, 319: 167-177.

Dixon, D., A. Pruski, L. Dixon \& A.N. Jha. 2002. Marine invertebrate eco-genotoxicology: a methodological overview. Mutagenesis, 17 (6): 495-507.

Dolcetti, L. \& P. Venier. 2002. Susceptibility to genetic damage and cell types in Mediterranean mussels. Marine Environmental Research, 54: 487-491.

Lee, R.F. \& S. Steinert. 2003. Use of the single cell gel electrophoresis/ comet assay for detecting DNA damage in aquatic (marine and freshwater) animals. Mutation Research, 544: 43-64.

Majone,F., R. Brunetti, I. Gola \& A. Levis. 1987. Persistence of micronuclei in the marine mussel, Mytilus galloprovinciales after treatment of mitomycin C. Mutation Research, 191: 157-161.

Majone,F., C. Beltrame \& R. Brunetti. 1988. Frequencies of micronuclei detected on Mytilus galloprovinciales by different staining techniques after treatment with zinc chloride. Mutation Research, 209: 131-134.

Mitchelmore, C.L \& J.K. Chipman. 1998. DNA strand breakage in aquatic organisms and the potential value of the comet assay in environmental monitoring. Mutation Research, 399: 135147.
Mitchelmore, C.L., C. Birmelin, D.R. Livingstone \& J.K. Chipman. 1998. Detection of DNA strand breaks in isolated mussel (Mytilus edulis L.) digestive gland cells using the «comet» assay. Ecotoxicology and Environmental Safety, 41: 51-58.

Nadin, S., L. Vargas-Roig \& D. Ciocca. 2001. A silver staining method for single-cell gel assay. The Journal of Histochemistry and Cytochemistry, 49 (9): 1183-1186.

Ostling, O. \& K.J Johanson. 1984. Microelectrophoretic study of radiation-induced DNA damages in individual cells. Biochemical and Biophysical Research Communications, 123: 291-298.

Pavlica M, G.I.V. Klobuèar, N. Moja, R. Erben \& D. Pape. 2001. Detection of DNA damage in haemocytes of zebra mussel using comet assay. Mutation Research 490: 209-214.

Ralph, S., M. Petras, R. Pandrangi \& M. Vrzoc. 1996. Alkaline single cell gel (comet) assay and genotoxicity monitoring using two species of tadpoles. Environmental and Molecular Mutagenesis. 28: 12-120.

Rank,J. \& K. Jensen. 2003. Comet assay on gill cells and hemocytes from the blue mussel Mytilus edulis. Ecotoxicology and Environmental Safety, 54: 323-329.

Scarpato,R., L. Migliore, G. Alfinito-Cognetti \& R. Barale. 1990. Induction of micronuclei in gill tissue of Mylitus galloprovincialis exposed to polluted marine waters. Marine Pollution Bulletin, 21 (2): 74-80.

Schmid, W. 1975. The micronucleus test. Mutation Research, 31: 9 15.

Shugart, L. 1990. Biological monitoring: testing for genotoxicity. In: McCarthy JF, Shugart LR, editors. Biomarkers of environmental contamination. Lewis, Chelsea; p. 217-27.

Singh, N.P., M.T. McCoy, R.R. Tice, \& E.L. Scheider. 1988. A simple technique for quantitation of low levels of DNA damage in individual cells. Experimental Cell Research, 237: 123130.

Singh, N.P. \& R.E. Stephens. 1997. Microgel electrophoresis: Sensitivity, mechanisms, and DNA electrostretching. Mutation Research, 383: 167-175.

Venier, P., S. Maron \& S. Canova. 1997. Detection of micronuclei in gill cells and haemocytes of mussels exposed to benzo(a)pyrene. Mutation Research, 390: 33-44.

Wilson, J.T., P.L. Pascoe, J.M. Parry \& D.R. Dixon. 1998. Evaluation of the comet assay as a method for the detection of DNA damage in the cells of a marine invertebrate Mytilus edulis L. (Mollusca: Pelecypoda). Mutation Research, 399: 8795.

Wrisberg, M.N., C.M. Bilbo \& H. Spliid. 1992. Induction of micronuclei in hemocytes of Mytilus edulis and statistical analysis. Ecotoxicology and Environmental Safety, 23: 191205. 
